Printed

September 11, 1990
RFP-4300

UC-704 MATERIALS

DOE/OSTI-4500 (Rev. 75)

RFP- -4300

DE91 002533

\title{
X-RAY DIFFRACTION MEASUREMENT OF RESIDUAL STRESSES IN DELTA PLUTONIUM
}

\author{
P. A. Steinmeyer
}

SUBJECT DESCRIPTORS

X-Ray Diffraction

Stress Measurement

Plutonium

EG\&G ROCKY FLATS, INC.

ROCKY FLATS PLANT

P. O. BOX 464

GOLDEN, COLORADO $80402-0464$

\footnotetext{
PREPARED UNDER CONTRACT DE-AC04-90DE62349

FOR THE

ALBUQUERQUE OPERATIONS OFFICE

U.S. DEPARTMENT OF ENERGY
}

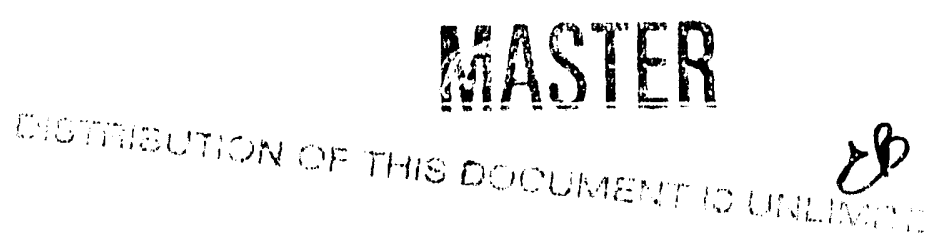




\section{ACKNOWLEDGMENTS}

The author expresses gratitude to Frank Gibbs, Plutonium Metallurgy, for assistance preparing the bending beam sample and to Carl Edstrom, General Metallurgy, for helping with the tantalum anode design. Thanks are also due Don Livesay for expediting the anode fabrication. Aclual machining operations were conducted by Mike Bogard and Gorden Otson, Assembly Systems. 


\section{CONTENTS}

Abstract .................................................................. 1

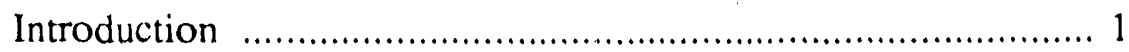

Diffractometer Considerations ......................................... 1

Stress Measurement in Delta Plutonium ............................. 2

Experimental ............................................................ 2

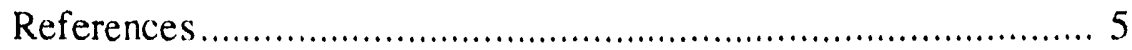




\title{
X-RAY DIFFRACTION MEASUREMENT OF RESIDUAL STRESSES IN DELTA PLUTONIUM
}

\author{
P. A. Steinmeyer
}

\begin{abstract}
Residual stresses in delta plutonium can be measured by the X-ray diffractometer method. This was accomplished with the aid of an experimental tantalum $\mathrm{X}$-ray target. Preliminary experiments are encouraging and indicate that stresses may be determined precisely and rapidly. Future work will involve determination of $\mathrm{X}$-ray clastic constants, instrument calibration with stress-free standards, higher X-ray power and more sophisticated monochromatization methods.
\end{abstract}

\section{INTRODUCTION}

$\mathrm{X}$-ray diffraction is commonly used for nondestructive stress measurements in a wide variety of engineering matcrials. Until now, however, this technique has not been applied to delta plutonium. This report summarizes a preliminary investigation by the Rocky Flats Plant Physical Metallurgy group into the feasibility of $\mathrm{X}$-ray stress measurement on delta plutonium.

The measurement of residual stresses by X-ray diffraction is based on detection of the change in interplanar spacing with elastic strain. ${ }^{1}$ In a diffractometer experiment, this spacing change is measured as a diffraction peak shift. The diffractometer configuration for the usual parafocus geometry is shown in Figure 1. The specimen undergocs a rotation (denoted as $\Psi$ ) about the diffractometer axis. A particular (hkl) reflection is scanned in the normal inclination $(\Psi=()$ and again at a much higher inclination angle (typically 45 to 60 degrrees).

This procedure allows a change in interplanar spacing between (hkl) planes inclined at an angle $\Psi$ to the surface to be measured. If it is assumed that the stress component normal to the surface is zero, then using simple geometric calculations, a strain component parallel to the sample surface can be obtained. ${ }^{2,3}$ If a
Hooke's law stress-strain behavior is assumed, then a stress value can be calculated using the measured strain and the appropriate clastic constants.

\section{DIFFRACTOMETER CONSIDERATIONS}

A diffractometer is most sensitive to small variations in lattice spacing when the measured (hkl) peak lics in the high back reflection region, preferably with $2 \theta$ $>150$ degrees. Most commercial diffracte .ters have an upper $2 \theta$ limit of 160 degrees or less. X-ray diffraction stress measurement studies are therefore usually conducted in the angular range $150<2 \theta<160$ degrees; thus, it is necessary for a particular (hkl) to select a radiation resulting in a suitable diffraction angle. In addition, the (hkl) reflection must be of high enough intensity to give a reasonably high count rate. It is often difficult to meet these requirements simultaneously, and a compromise combination of target radiation and (hkl) must often be chosen.

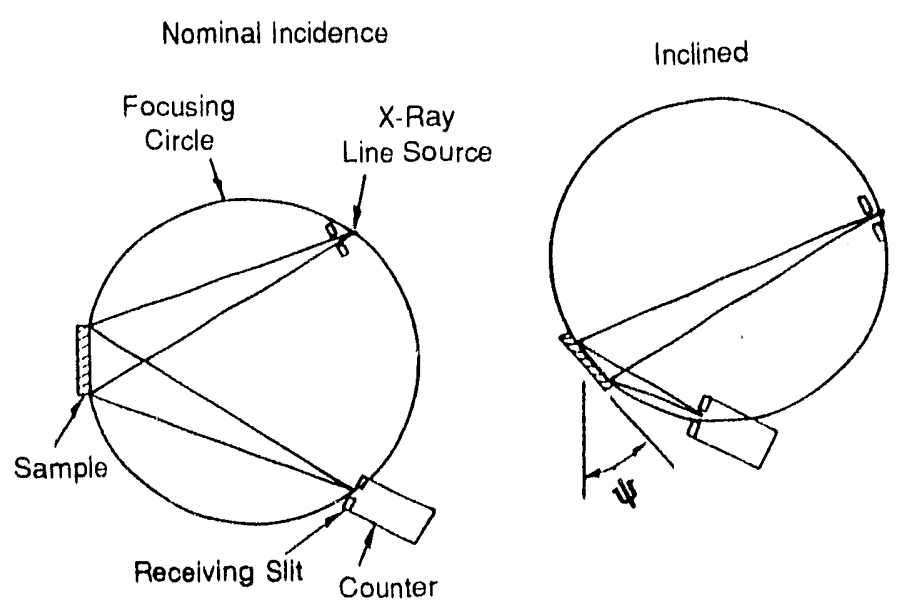

FIGURE 1. Diffractometer Optics for Delta Plutonium Stress Measurement. The maximum inclination angle was, 60 degrees. To maintain focusing conditions, the detector was moved forward during sample tilt. 


\section{STRESS MEASUREMENT IN DELTA PLUTONIUM}

Delta-phase stabilized plutonium has a face-centered cubic crystal structure with a lattice parameter of $4.62 \AA$ (Reference 4). Lattice spacings of delta plutonium crystallographic planes are listed in Table 1. Diffraction angles with various $\mathrm{X}$-ray targets are also tabulated. It would be very desirable to use the (531) plane in combination with a copper target because the $2 \theta$ angle of 162 degrees would result in high stress sensitivity. Unfortunately, the diffractometer in our laboratory has an upper angle limit of 157 degrees.

If a standard X-ray target is used, then a less suitable diffraction line (at a lower angle) must be measured. This approach was taken in a preliminary study with less than satisfactory results. In this instance, the (511) line was used with copper $\mathrm{K} \alpha$. radiation, and the diffraction angle was 120 degrees. This low angle resulted in very poor sensitivity.

The only alternative is to fabricate a special X-ray target from one of the candidate materials listed in Table 1. The tantalum-L $\alpha$ line, used in conjunction with the (531) reflection, gives a diffraction angle of about 153 degrees, which is within the diffractometer range and is also high enough to ensure adequate sensitivity. Furthermore, tantalum is an attractive $X$-ray target material because of its refractory nature. For these reasons, it was decided to fabricate a tantalum $\mathrm{X}$-ray target for the express purpose of plutonium stress measurement.

\section{EXPERIMENTAL}

The Physical Metallurgy diffraction laboratory uses Rigaku rotating anode X-ray generators with demountable targets, allowing a replacement tantalum target for experimental purposes. Tests indicated that the target functioned as intended, piving a strong $L \alpha$ line with good spectral purity. It was estimated that the anode could operate at input up to $12 \mathrm{~kW}$. However, because the target was experimental, it was operated at a maximum of $3.5 \mathrm{~kW}$ to avoid possible larget damage.

The experimental sample was a plutonium-gallium bar $2 \mathrm{~cm} \times 14 \mathrm{~cm} \times 0.23 \mathrm{~cm}$. The sample was prepared by casting a $0.76-\mathrm{cm}$-thick feed finger, rolling $100.23 \mathrm{~cm}$, and anncaling at 440$)^{\circ} \mathrm{C}$ for eight hours. A light final roll pass was used for straightening. Final grain sizc was approximately 45 microns. The specimen surface was prepared by light grinding and electropolishing. Then, the entire bar was wrapped in six-micron mylar film to avoid relcase of plutonium oxides.

The bar was placed in a four-point bending beam fixture, as shown in Figure 2. This fixture allows determination of diffraction peak shifts as a function of known clastic beam deflection.

With a dial indicator, the specimen surface was aligned on the diffractometer axis, and a diffractometer trace was obtained for referenice. This diffractometcr data, as well as all stress measurement data, were taken under the following conditions:

TABLE 1. Potential X-Ray Targets for Delta Plutonium Stress Measurement

\begin{tabular}{|c|c|c|c|c|c|c|c|c|c|c|}
\hline (hkl) & $\underline{1 / 10}$ & $d(\AA)$ & Pól $\alpha$ & $\underline{\text { Sck } \alpha}$ & CoKa & $\underline{\text { NiK } \alpha}$ & CuKa & $\underline{\operatorname{ZnK} \alpha}$ & $\underline{\text { Tal } \alpha}$ & WI, $\underline{\underline{n}}$ \\
\hline 111 & 100 & 2.664 & - & - & - & - & .- & -- & -- & -- \\
\hline 200 & 60 & 2.308 & 142.3 & - & - & - & .- & -- & $\cdots$ & -. \\
\hline $2<0$ & 35 & 1.632 & - & 136.5 & -- & - & -. & -- & .. & -- \\
\hline 311 & 50 & 1.391 & - & - & -- & -. & - & -- & -. & -- \\
\hline 422 & 40 & 0.942 & - & - & 143.4 & -- & - & -- & - & -. \\
\hline 511 & 30 & 0.888 & - & - & - & 137.9 & 120.3 & -. & -. & .. \\
\hline 531 & 85 & 0.780 & -- & -. & - & .. & 161.8 & 133.8 & 154.6 & 142.3 \\
\hline
\end{tabular}


Tantalum L $\alpha$ X-ray source, $50 \mathrm{kV}, 70 \mathrm{~mA}$, line focus $250-\mathrm{mm}$ diffractometer radius $(105 \mathrm{~mm}$ at $\psi=60$ degrees)

10-micron nickel filter

Scintillation counter

Pulse height analyzer set for $90 \%$ acceptance of tantalum $L \alpha$ line

2-degrec divergence and scatter slits

5 -degree soller slits

0.068 -degree receiving slit

Step scan parameters: 0.1 degree/step, $10 \mathrm{sec} / \mathrm{step}$
The diffractometer trace is shown in Figure 3, and the peak-to-background ratio for the (531) peak is about $2: 1$. Thus, counting statistics were mediocre, caused by the high background from the simple monochromatization (filter/pulse height analyzer). Still, conditions were adequate for approximate measurements.

Next, the two-exposure diffractometer technique was used to measure the (531) diffraction peak shift at various beam deflections. Intensity data were

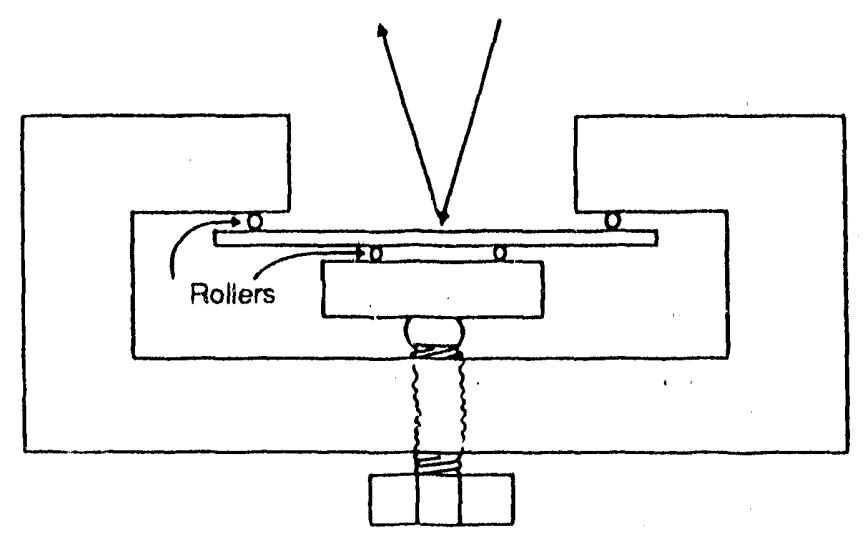

FIGURE 2. Four-point Bending Beam Fixture for Plutonium Stress Measurement Calibration. The sample face exposed to the $\mathrm{X}$-ray beam is placed directly over the diffractometer axis with a dial indicator.

FIGURE. 3. Diffractometer Trace for Delta Plutonium Stress Sample. Radiation used was tantalum $L \alpha$. The far right peak is the (531) reflection used for stress measurement.

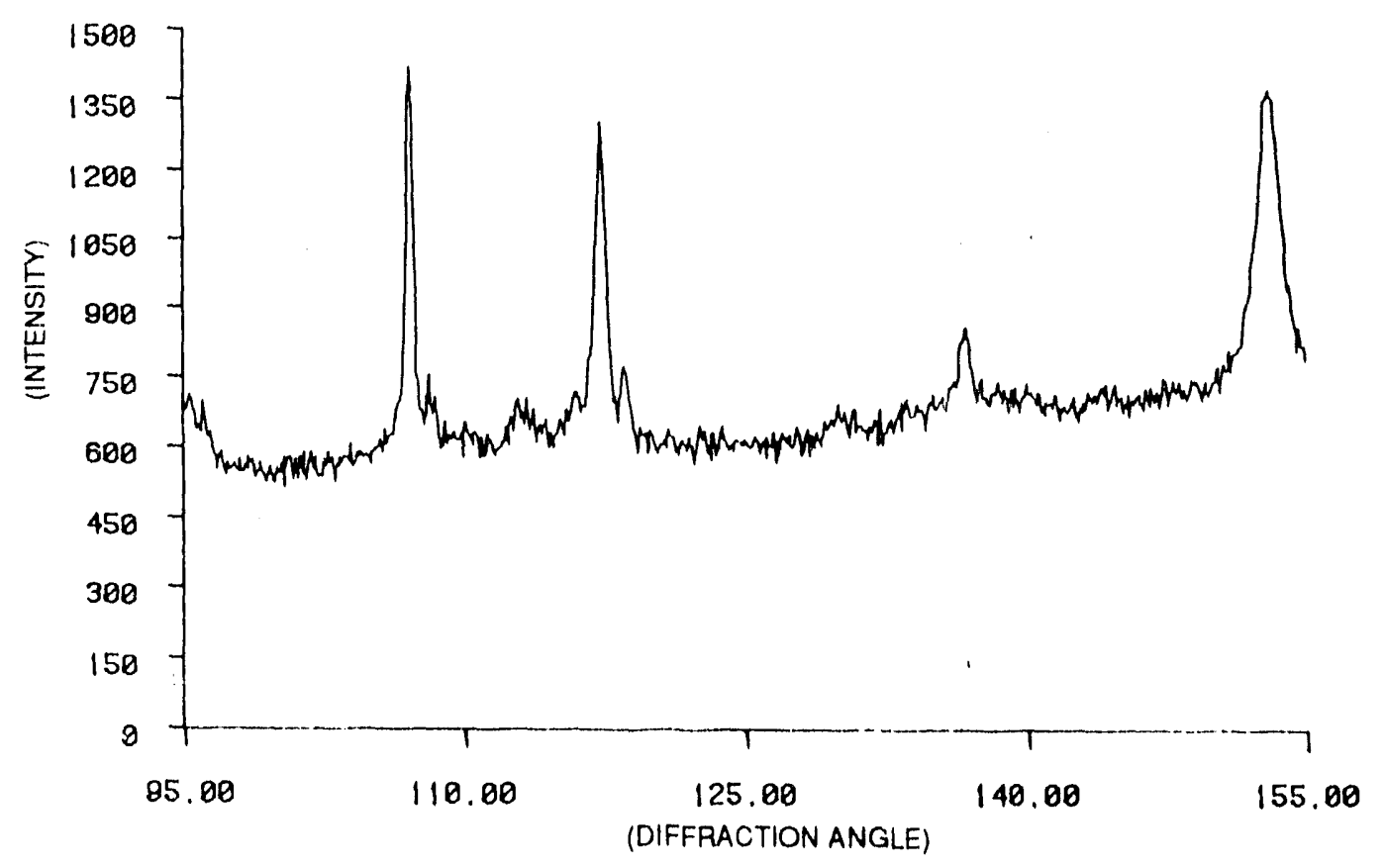


corrected for Lorentz and polarization factors, and peak centers were determined by the live-point parabola fitting method. Because of the wide separation of the tantalum L $\alpha$ X-ray lines, the question of doublet resolution normally encountered with a $\mathrm{K} \alpha$ radiation was not a factor. Results of the bending beam experiment (Figure 4) indicate the observed peak is a linear function of beam deflection.

To obtain a working curve, further measurements will be taken on a specimen approximately free from macrostress. In most enginecring mallerials, this is accomplished by laking peak shift measurements on annealed powder samples. Of course, this is not possible with plutonium, and a "zero stress" sample will probably be approximated, using an annealed bulk specimen after thorough electropolishing.

It is interesting to consider the stress equation as applied to this experiment. Stress (in psi) is given by:

$$
\sigma=\mathrm{K} \cdot \Delta 2 \theta
$$

where $\Delta 2 \theta$ is the measured peak shift in degrees, and $K$ is the stress factor (psi/degrec), defined as:

$$
K=\frac{E \cot \theta}{2(1+v) \sin \psi} \cdot \frac{\pi}{180}
$$

where $\mathrm{E}=$ clastic modulus $=6.2 \times 10^{\prime} \mathrm{psi}$

$\theta=$ Bragg angle $=76.5$ degrees

$\Psi^{\prime}=$ Specimen tilt angle $=6()$ degrees

$v=$ Poisson's ratio $=0.3$

Small values of the stress factor indicate high sensitivity, meaning that small residual stresses will result in relatively large peak shifts. Such is the case he re; the calculated stress factor under the above conditions is $11,5(0) \mathrm{psi} / \mathrm{degrec}$. By way of comparison, steel examined under typical $X$-ray conditions has a stress factor of $55,00(0-85,000 \mathrm{psi} / \mathrm{degree}$. The stress factor is low for plutonium because of the high diflaction angle, the high angle of tilt, and especially the low clastic modulus. Since the minimum observable peak

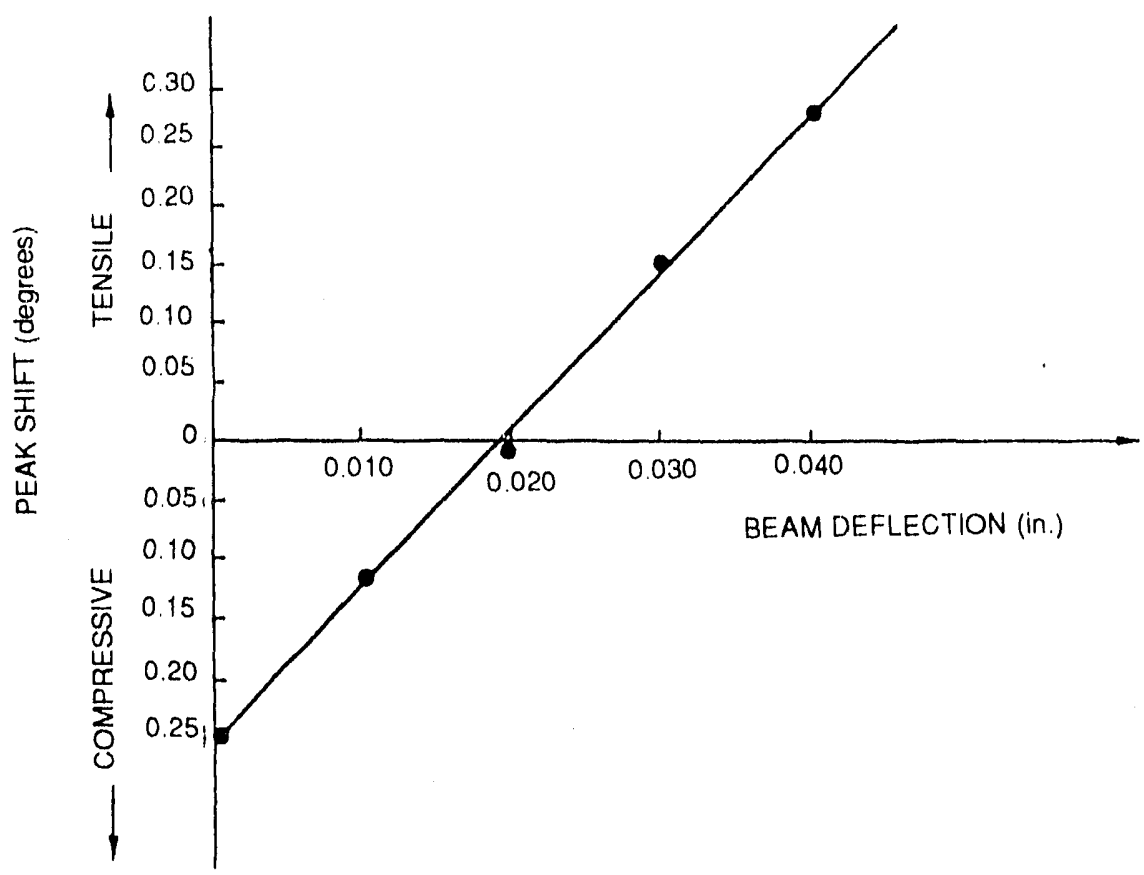

FIGURE 4. Peak Shift as a Function of Beam Deflection for Delta Plutonium Sample. The (531) peak was used for all measurements. Sample inclinations were () and $(x)$ degrees. 
shift is about 0.02 degrees (using peak fitting), the corresponding minimum detectable stress is about 230 psi. In other words, the X-ray method when applied to delta plutonium is a very sensitive technique.

Even though experimental conditions were not ideal, the observed peak shift/beam deflection curve is nearly linear, and the amount of scalter is very small. Subsequent tests will be conducted under more favorable conditions. For example, the X-ray target in this study was operated at about $30 \%$ of maximum power, while later work will be conducted at full power.

Furthermore, lechniques are available for much more efficient monochromatization, which will enhance the peak-to-background ratio. These refinements may be necessary if stresses are measured ir actual parts, because production part surfaces may have significant cold work or surface roughness, making the diffraction peaks diffuse.

Subsequent work will also involve actual determination of the X-ray modulus. Elastic moduli, as determined by $\mathrm{X}$-ray methods, can differ significantly from bulk values. Consequently, it is desirable to use an experimentally measured $\mathrm{X}$-ray modulus in the stress equation.

\section{REFERENCES}

1. Residual Stress Measurement by X-Ray Diffraction, Report J784a, Socicty of Automotive Enginecrs, August 1971.

2. B. D. Cullity, Elements of X-Ray Diffraction, p 4,50. Addison-Weslcy Publishing Company, Rcading, MA, 1967.

3. X-Ray Subcommittee of SAE Iron and Techrical Committee, Division 4, Society of Automotive Enginecrs, November 1964.

4. O. J. Wick (Ed.), Plutonium Handbook I, p 82, Gordon and Breach, New York, NY, 1967. 

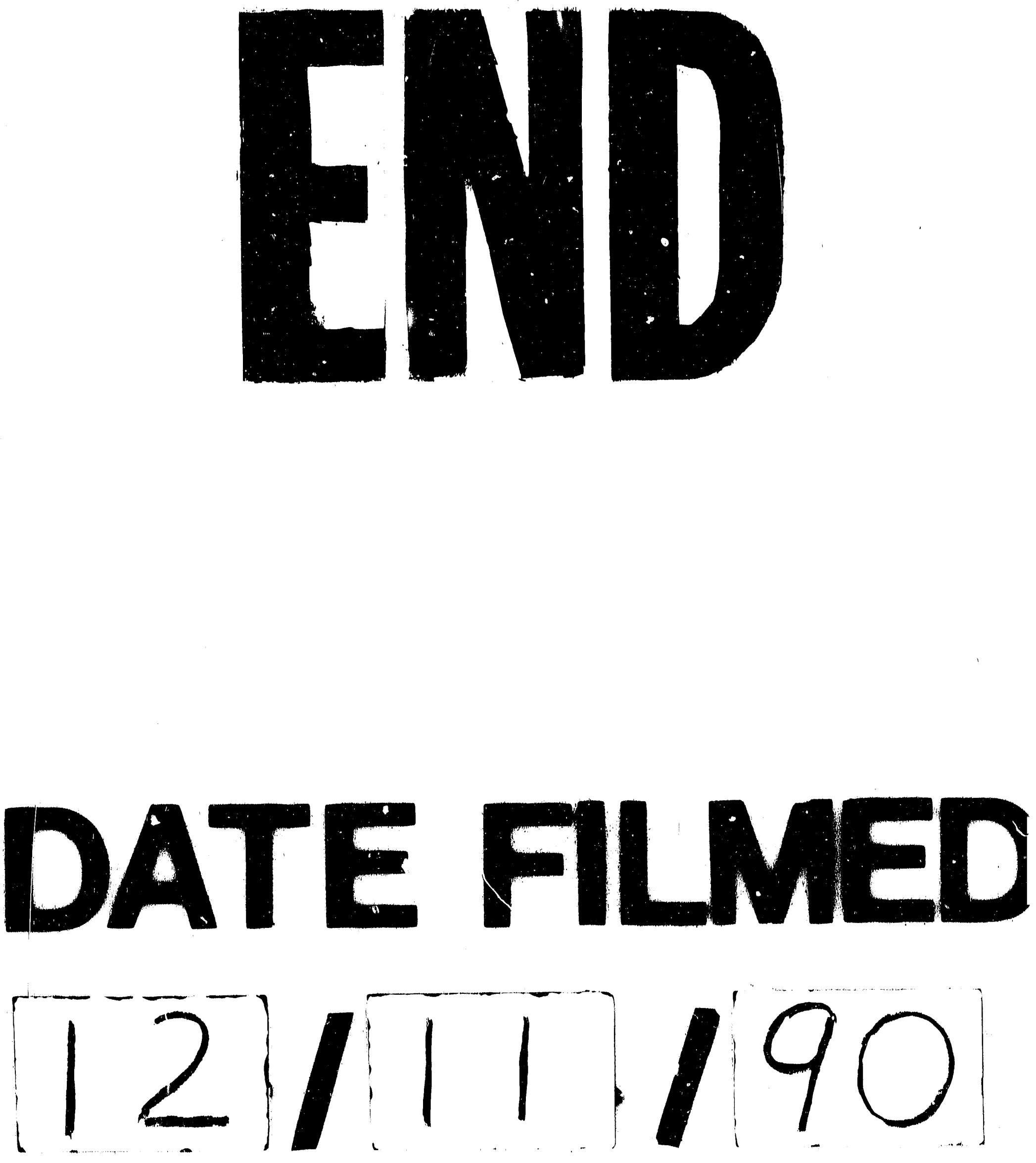
